\title{
Kovesi on natural world concepts and the theory of meaning
}

\section{Alan Tapper}

Julius Kovesi was a moral philosopher whose work rested on a theory of concepts and concept-formation, which he outlined in his 1967 book Moral Notions. ${ }^{1}$ Kovesi took the view that to revive moral philosophy from the dismal state it had reached in midcentury, it was necessary to rethink the role of moral concepts in our social life. He was one of a number of moral philosophers who were then reconstructing moral philosophy. ${ }^{2}$ All of these thinkers sought to give the virtues their proper place in ethics; all rejected the supposed fact-value dichotomy; all were concerned to take seriously the history of moral thought. Kovesi shared these concerns, but his contribution to the reconstruction is, as Philippa Foot has observed, a very distinctive one. ${ }^{3}$ She says that

\footnotetext{
[his] theory of morals ... is radically different from anything else on the scene, then [1967] or now. What is the difference? First and foremost it is that where contemporary moral philosophers have as their starting point an account of what an individual speaker is doing (as, for example, expressing an attitude or issuing a prescription) when he or she praises or condemns an action, Julius starts much further back with an account of the formation of a particular kind of concept.
}

\footnotetext{
${ }^{1}$ Julius Kovesi, Moral Notions (London: Routledge and Kegan Paul, 1967); republished as Moral Notions, with Three Papers on Plato, R.E. Ewin and Alan Tapper eds, (Christchurch: Cybereditions, 2004), with a Foreword by Philippa Foot and an Afterword by Ewin and Tapper, pp. 143-174. (Hereafter, MNP.)

${ }^{2}$ Amongst those closest to him were Mary Midgley and Philippa Foot. Others less close included Alasdair MacIntyre, Charles Taylor, Bernard Williams, Iris Murdoch, Peter Geach and Elizabeth Anscombe.

${ }^{3} M N P$, p. ix.
} 
The main distinctiveness is his focus on moral concepts, a focus less prominent in the other philosophers.

This distinctive focus, Kovesi thought, was what he had learned from his reading of Plato. ${ }^{4}$ Thus, his method for approaching ethics was not just an application of ordinary language philosophy or of Wittgensteinian 'language game' semantics to the moral domain - which are the natural interpretations to give to Kovesi's thought, given his Austinian training in 1950s Oxford. But his contribution goes further than this. In sketching a theory of concepts and concept-formation, he was entering the philosophy of language. To make his account of moral concepts credible, he needs a broader story about how moral concepts compare with other sorts of concepts. Yet philosophy of language, once dominated by Wittgenstein and Austin, came rather suddenly in the 1960s to be dominated by metaphysicians and philosophers of science trying to give an account of natural science concepts. How then does Kovesi's theory of concepts fare when viewed in the light of this shift of interests? Does he have a theory of natural world concepts that can stand scrutiny? I will try to show that he does. To show this, I will focus on the concept of water. However, before doing this we need an outline of Kovesi's account of what he called 'notions formed about the inanimate world'.

Just as in his discussion of moral concepts he used an invented concept misticket, ${ }^{5}$ so in this discussion he used the invented concept $t a k .{ }^{6} \mathrm{~A}$ tak is a supposed meteorological phenomenon:

\footnotetext{
a meteorologist may have been puzzled by a certain phenomenon and after careful observations at last connects the phenomenon with certain cloud-formations. He discovers that the phenomenon occurs five minutes after a cloud-formation which has a pointed projection. He selects these features of clouds because they enable him to perform the activity of predicting the phenomenon in question. Then he may coin the word 'tak' to refer to these cloud-formations if this is the word he wants to use to present his findings. Later, when he
}

\footnotetext{
${ }^{4}$ See his interpretation of Plato in MNP, pp. 119-141; and also the discussion of it in this volume by Mooney and Churchman.

${ }^{5}$ See MNP, pp. 36-44.

${ }^{6}$ He also used the invented concept wousin, derived from C.K. Ogden and I.A. Richards, The Meaning of Meaning: A Study of the Influence of Language Upon Thought and of the Science of Symbolism (London: Routledge and Kegan Paul, 1949), p. 46. However, this is a social science concept, not a natural science concept.
} 
teaches what taks are he will be teaching at the same time the rules for predicting the phenomenon in question. People would not know what taks were if they could only recognize the cloud-formations but did not know that five minutes later a certain phenomenon will occur. We do not, then, first have words with 'neutral descriptive criteria' - or recognitors, as I would like to say - and then load them with a theory, but we select the recognitors because they are relevant to the activity in which the word will play a role. 'Tak' means more than 'being a shape with a pointed projection'. The meteorologist would rightly object to the suggestion that what 'tak' really meant was a certain sort of observable shape, or that the observable shape is the fact and the rest is added theory.

Let us suppose that during his investigations our meteorologist observed that the phenomenon occurred either five minutes after a cloud-formation with a pointed projection or five minutes after a cloud-formation when there is a hole through the cloud. In this case taks would be clouds either with a pointed projection or with a hole through them. Being a good scientist he would present his findings by saying that so far he has discovered these two different types of taks. In future he might discover other cloud-formations that look empirically different from the hitherto known taks; nevertheless they amount to the same, they are also taks. This is in line with the conclusion ... that it is the formal element of a notion that enables us to decide what will or will not amount to the same thing. ${ }^{7}$

In this short discussion of concept-formation, the key points are that being able to recognise an $\mathrm{X}$ is not the same as knowing what an $\mathrm{X}$ is or knowing the meaning of ' $X$ '; that any X-type phenomenon may turn out to be exemplified by various kinds of $\mathrm{X}$; and that to successfully form a concept we first need to have a reason or purpose or point in doing so (which he also calls the 'formal element' of the concept), such reasons being derived from the activities we publicly engage in, such as meteorology, or science more generally, where the point of the activity is prediction and explanation of the natural world. ${ }^{8}$ Kovesi will go on to argue that exactly the same applies in the moral realm, except that the point of the activity is a different one. ${ }^{9} \mathrm{He}$ also contends that our shared activities can have a number of different points or purposes. Concepts may be formed from functional, prudential, legal, moral and scientific viewpoints. Our conceptual system is not divided simply into moral concepts and natural science concepts. ${ }^{10}$

\footnotetext{
${ }^{7}$ MNP, pp. 33-34.

${ }^{8}$ See $M N P$, pp. 30-36, for the general argument.

${ }^{9} M N P$, pp. 36-44.

${ }^{10}$ MNP, p. 48. See also p. 105.
} 
With these points in mind we can turn to what other philosophers, writing at much the same time, have said about meaning and concept-formation. In this discussion, the key example is an actual concept, the concept of water, though an invented concept, designated 'XYZ', is also a key part of the discussion. We will argue that Kovesi's account of concepts and meaning shed valuable light on this discussion.

\section{Philosophers and Water}

Since Hilary Putnam’s 1975 essay on 'The Meaning of “Meaning”, philosophers have had a great deal to say about water and the concept of water. ${ }^{11}$ In the subsequent discussions, most of them (though not all) have taken it as given that in some strong sense water is $\mathrm{H}_{2} \mathrm{O}$. The reason why water has been so prominent is this: water as we commonly know it has a collection of superficial properties - it is wet, fluid, transparent, and it supports the life of plants and animals, including and especially our human lives. But water also has a chemical constitution, as was discovered in the late eighteenth century by Priestley, Watt, Cavendish and Lavoisier. ${ }^{12}$ Water, they discovered, is $\mathrm{H}_{2} \mathrm{O}$. The philosophical topic of interest has been, roughly speaking, the relation between the superficial pre-scientific understanding of the concept of water and the scientific understanding.

Putnam proposed that we imagine a substance that has exactly the same set of superficial properties but a different chemical constitution - he calls it 'XYZ'. Would this new substance really be water? The question creates a tension. If we say yes, then we have to allow that water is not by definition $\mathrm{H}_{2} \mathrm{O}$; it is $\mathrm{H}_{2} \mathrm{O}$ only contingently. If we say no, then water is not necessarily whatever has these superficial properties, and, thus, for centuries human beings did not understand the true concept of water.

\footnotetext{
${ }^{11}$ Hilary Putnam, 'The Meaning of "Meaning”', Mind, Language and Reality: Philosophical Papers, vol 2 (Cambridge: Cambridge University Press, 1975), pp. 215-271. See also The Twin Earth Chronicles: Twenty Years of Reflection on Hilary Putnam's 'The Meaning of "Meaning"', Andrew Pessin, Sanford Goldberg, eds (New York: M.E. Sharpe, 1996), which includes 'The Meaning of "Meaning".

${ }^{12}$ John Warltire should be added to this pantheon. He was probably the first to decipher the chemistry of water.
} 
My argument will be four-fold. Firstly, I will contend that we can and should distinguish between two concepts of water: what I will call the everyday concept and the scientific concept. I will draw this distinction quite sharply. Secondly, I will claim that the everyday concept of water corresponds to a kind of $\mathrm{H}_{2} \mathrm{O}$, but only one kind. The other kinds of $\mathrm{H}_{2} \mathrm{O}$ are ice, snow and steam. Thus, the everyday concept of water is not simply equivalent to the concept of $\mathrm{H}_{2} \mathrm{O} .{ }^{13}$ Thirdly, in my view the scientific concept of water is not reducible to $\mathrm{H}_{2} \mathrm{O}$, because as a matter of scientific fact there is more than one kind of water. From a scientific viewpoint, $\mathrm{H}_{2} \mathrm{O}$ is a kind of water, but not the only kind. Thus, the commonly assumed conceptual equivalence also breaks down in the scientific discourse. Fourthly, I will try to show how these contentions arise naturally from a Kovesian understanding of concepts and help solve the puzzles presented by Putnam's account of the concept of water.

Putnam's discussion of water presents us with a dilemma. Should we say that the meaning of 'water' is not carried around in our heads, but is really in the world that is, in the world of chemical constitutions? Yet it is hard to deny that concepts are rule-governed social and intellectual constructs. That, at least, was the widely influential teaching of Wittgenstein and Austin. We seem to have here a fundamental divide, one that any credible theory of concepts must confront. My suggestion is that a Kovesian approach to concepts shows us how to handle this dilemma. Kovesi's approach to any concept was to ask: what is the point of the concept? Or, rephrasing this: for what reason or reasons did we form this concept? Those are ways of expressing his general quest for the 'formal element' of the concept. To make progress with Putnam's problem, we must think about the formal element of the concept of water.

\section{'Water' in the Everyday Sense}

The concept of water, I suggest, has two main roles or functions - that is, in Kovesian terms, it has two formal elements. It is, and always has been, a member of the family

\footnotetext{
${ }^{13}$ This point has been made once or twice before, but usually as not much more than a throwaway line, whereas I think it should be taken seriously.
} 
of food concepts. ${ }^{14}$ Nowadays, it is also a member of the family of chemical concepts. The two are in some sort of philosophical tension, though I am far from sure that, outside of philosophy, anyone is ever in any real quandary about these two interpretations of the concept.

Is the everyday meaning of 'water' at all closely related to what we understand as ' $\mathrm{H}_{2} \mathrm{O}$ '? Everyday usage is strongly against this idea. Imagine, for example, that a waiter brings you a glass of ice cubes when you requested a glass of water. Yes, it is $\mathrm{H}_{2} \mathrm{O}$, but no, it is not water. If at the bar I ask for ice in my whisky, I am not asking for water in my whisky. I won't succeed in watering my plants by dumping ice on them. For the purposes of 'watering', ice is not water, and neither is snow, even though ice and snow are forms of $\mathrm{H}_{2} \mathrm{O}$. If I ask for a bucket of water for my plants, a bucket of ice or steam will not be taken as a bucket of water. The sentence: 'The penguin jumped off the ice shelf into the turbulent water' can’t be replaced with 'The penguin jumped off the water shelf into the turbulent ice'.

In the everyday sense of the word, 'water' means 'liquid water'. Only liquid water is 'watery'. It is true that liquid water is made up of $\mathrm{H}_{2} \mathrm{O}$, but it is only one kind of $\mathrm{H}_{2} \mathrm{O}$. Ice, snow and steam are other kinds of $\mathrm{H}_{2} \mathrm{O}$. Water is $\mathrm{H}_{2} \mathrm{O}$ only in the weak sense of class membership, and not in the strong sense of conceptual equivalence. In everyday usage we draw a distinction between water and other things that are made of $\mathrm{H}_{2} \mathrm{O}$. Water is $\mathrm{H}_{2} \mathrm{O}$, but so also is ice, and - as my illustrations suggest - ice is not water. You might doubt this. Ice, you might say, is frozen water, and therefore ice is water. But this is mistaken. Ice is made from water. Once the water has been frozen it has ceased to be water, in the everyday sense of the word. In this sense of the word, 'liquid water' is the only kind of water. The case nicely illustrates the doctrine that meaning is a matter of common public usage. If we attend to how the concept of water is actually used, we get the seemingly paradoxical conclusion that frozen water is not water!

\footnotetext{
${ }^{14}$ We seem to lack a common English word for food-and-drink. 'Victuals' and 'comestibles' sound quaint. 'Foodstuffs' is not quite right. Hence, I will simply use 'food' as the general category, even though it sounds wrong for drinks.
} 
Why should we draw this distinction between water and other kinds of $\mathrm{H}_{2} \mathrm{O}$ so strongly? Because our everyday concept of water is not merely a pre-scientific standin, a nominal essence waiting to be given its correct real essence when modern science gets going. The everyday concept of water is, and always has been, a member of the family of food concepts. More broadly, food concepts are part of the lifesustaining lexicon. Ice, snow and steam are not life-sustaining substances; water is. Of course, ice, snow and steam can become life-sustaining by conversion to (liquid) water. Distinguishing between that which is life-sustaining and that which is not is one of the first things any conceptual system needs to do. Conceptual beings such as ourselves would not survive unless we made these distinctions. For this reason, our food concepts, including our everyday concept of water, cannot be superseded by our scientific concepts, which are about substances that are often indifferent to human survival interests. Whatever we think about Putnam's problem we should not fall into the mistake of downgrading the conceptual credentials of the food concept of water. This is the wrong way to go. We still certainly need that concept.

Putnam misses this simple point about the concept of water, ${ }^{15}$ but his discussion of lemons touches on the point I am making. He considers, and then rejects, the suggestion made by an unnamed critic that 'the predominant sense of ... "lemon" is the one in which anything with (a sufficient number of) the superficial characteristics of a lemon is a lemon'. About this I agree with Putnam that it mistakenly takes the features by which we might recognise lemons for properties by which we understand the concept 'lemon'. Putnam rejects his critic's view because it would seem to entail that silicon-based lemons and machine-made 'lemons', if they have the standard superficial qualities, are lemons just as much as tree-grown lemons. Putnam adds that 'The same critic has suggested that having the hidden structure - the genetic code - of a lemon is necessary to being a lemon only when "lemon" is used as a term of science, ${ }^{16}$ About this, the critic's view is close to mine. The case is similar to that of water in that lemons, like water, are valued as food. For the purposes of eating and cooking, it doesn't matter what the genetic code of the species happens to

\footnotetext{
${ }^{15}$ Curiously, although Putnam thinks that water is $\mathrm{H}_{2} \mathrm{O}$, he also thinks that it is a 'semantic marker' - a term somewhat similar to Kovesi's 'formal element' - for the concept of water that water is a liquid. See Mind, Language and Reality, p. 269. He does not discuss the status of non-liquid 'water' such as ice, snow or steam.

${ }^{16}$ Putnam, 'The Meaning of "Meaning”, p. 239.
} 
be. Sometimes limes will do just as well; sometimes the Australian lemon myrtle will do; and if lemon flesh and juice could be synthesised, then we could perfectly well use that instead of lemons off a tree. ${ }^{17}$ But when we are growing lemon trees, it is very useful to think scientifically, even perhaps down to the level of the genetic code. Thus we also need a scientific concept of 'lemon'.

\section{'Water' as a Scientific Concept}

What then about the scientific concept of water? The question takes us to the chemistry of water. Is water, from a scientific viewpoint, simply equivalent to $\mathrm{H}_{2} \mathrm{O}$ ? Most of us naturally think that it is, and, for a century or more, this was scientific orthodoxy. But chemistry has moved on from the time of Priestley, Watt, Cavendish and Lavoisier. Today, the scientific concept of water is not definitionally reducible to $\mathrm{H}_{2} \mathrm{O}$. Standard $\mathrm{H}_{2} \mathrm{O}$ is not the only kind of water. In fact there are various other forms of water. There are, firstly, forms of heavy water. Heavy water, we are told, is water 'which contains a higher proportion than normal of the isotope deuterium, as deuterium oxide, $\mathrm{D}_{2} \mathrm{O}$ or ${ }^{2} \mathrm{H}_{2} \mathrm{O}$, or as deuterium protium oxide, $\mathrm{HDO}$ or ${ }^{1} \mathrm{H}^{2} \mathrm{HO}$. ${ }^{18}$ Not only that, but there are other forms of water: there are heavy-oxygen water, $\mathrm{H}_{2}{ }^{18} \mathrm{O}$; and tritiated water, also known as super-heavy water $\left({ }^{3} \mathrm{H}_{2} \mathrm{O}\right)$. The chemical structure of the various kinds of water differs from kind to kind. If this were not so then we would have only one kind of water; as it happens, we have a number of kinds, differentiated by their structural properties. The point that heavy water is water has been well made by Eddy Zemach: 'Water', he observes, includes any 'aggregates of T2O, HDO, HTO, and DTO molecules (the number of varieties is eighteen, since in each case the oxygen can be either O16, or O17, or O18). All these, we say, are different kinds of water' ${ }^{19}$

\footnotetext{
${ }^{17}$ Bernard Harrison has commented on this point: 'Suppose we bred limes which, while genetically limes, were physically and nutritionally indistinguishable from lemons? Suppose, again that this variety of lime occurred naturally? In the latter case, wouldn't the term 'lemon', used as a term in the food vocabulary, cease to have any connection with genetics?' I agree that it would.

${ }^{18}$ From the Wikipedia entry on 'heavy water'.

19 'Putnam's Theory on the Reference of Substance Terms', in The Twin Earth Chronicles, pp. 60-68; p. 62. For similar views on the semantics of scientific concepts, see D.H. Mellor, 'Natural Kinds', The Twin Earth Chronicles, pp. 69-80, and Tim Crane, 'All the Difference in the World', The Twin Earth Chronicles, pp. 284-304.
} 
These kinds of water are called water by chemists with good reason. They are all made only of hydrogen and oxygen. In fact the scientific concept of water seems to be a general category for any oxide of hydrogen. ${ }^{20}$ Naturally you would want to hear this from an expert rather than a philosopher before you put any credence in it. But my philosophical point will stand up fairly well even if the chemistry is amateurish. Scientists, it seems, are willing to use the concept of water as an umbrella category for a family of chemical types. The term 'water' does not map straight on to one and only one molecular type.

If this is right, then in the case of water science does not supply what the philosophers following Putnam seem to be looking for: an equivalence between a common semantic unit in ordinary usage and something narrowly-defined in the scientific lexicon. In fact, if we follow the scientific approach to this topic, the only thing that is equivalent to $\mathrm{H}_{2} \mathrm{O}$ is, it seems, $\mathrm{H}_{2} \mathrm{O}$ itself. True, for a century or so $\mathrm{H}_{2} \mathrm{O}$ did seem to be the only kind of water, and thus an equivalence did seem to hold. But it was provisional only. The chemists were open to new forms of water being discovered, and in fact they were discovered. ${ }^{21}$ This is a close parallel to Kovesi's story about the recognition of more than one kind of tak. ${ }^{22}$

\section{Conceptual Families}

So far I have been making two claims. One, the everyday concept of water, which is part of our food lexicon, denotes a kind of $\mathrm{H}_{2} \mathrm{O}$, but only one kind; ice, snow and steam are other kinds of $\mathrm{H}_{2} \mathrm{O}$. Thus, this everyday concept of water is not equivalent to $\mathrm{H}_{2} \mathrm{O}$. Two, the scientific concept of water is not equivalent to the concept of $\mathrm{H}_{2} \mathrm{O}$, because as a matter of scientific fact there is more than one kind of water. Thus, in scientific usage $\mathrm{H}_{2} \mathrm{O}$ is a kind of water, but not the only kind. Neither of these contentions seems controversial, though the philosophical debate about the concept of water has been conducted with insufficient attention to them. Note that I am not

\footnotetext{
${ }^{20}$ The obvious comparisons are with the oxides of carbon and the oxides of nitrogen. But for these compound families we lack vernacular umbrella terms comparable to 'water'.

${ }^{21}$ There are of course boundaries on what might be allowed to count as water. Sulphuric acid $\left(\mathrm{H}_{2} \mathrm{SO}_{4}\right)$ could never be counted as a kind of water, even though it is a transparent liquid and in part a chemical compound of hydrogen and oxygen. The formal element makes the difference here. Including it in the water family would defeat the point of using that concept.

${ }^{22}$ MNP, pp. 33-34.
} 
saying that once upon a time we had only the food concept of water and now we have two concepts. The concept of water also has an ancient proto-scientific lineage, being one of the ancient 'four elements': earth, air, fire, and water. In Western thought at least, water was long considered a basic stuff or substance. ${ }^{23}$ It was this concept that was being revised by the scientists of the late eighteenth century and further revised with the discovery of heavy water.

What does all this show about concepts and the theory of meaning? I have drawn a sharp distinction between what I have called two concepts of water. ${ }^{24} \mathrm{My}$ claim is that there are two concepts denoted by a single term. How can I justify this? Am I merely appealing to semantic intuitions here? My broader aim is to show that there is a Kovesian method behind these commonplace claims. Kovesi recommended asking - whenever we run into some conceptual difficulty - what would count as the same? Clearly, some other concepts lead double lives very similar to that of water. Salt and sugar, for example, feature on the dinner table and in the discourse of the laboratory. On the other hand, pepper and milk are confined to the food catalogue. Why? Because nothing of general explanatory value can be said about the chemical constitution of pepper and milk, whereas salt and sugar do have chemical coherence. This point illustrates something about the formal elements of the concepts of water, salt and sugar. These concepts are not mere 'descriptions'. They, unlike the concepts of pepper and milk, can be used in the explanatory enterprise of chemistry, as well as in the food lexicon. ${ }^{25}$ Following Kovesi, then, I am supposing that concepts belong in families. (A similar idea is that concepts belong in 'semantic fields'; alternatively, we may think of concepts as forming systems of classification.) As a general point, given any concept under discussion, we should always ask what is the family of concepts to which this concept belongs? The case of the concept of water is unusual in that it belongs to two families at once.

\footnotetext{
${ }^{23}$ It goes back at least as far as Empedocles (ca. 495-435 BCE), in his On Nature.

${ }^{24}$ Arguably, I should speak of two conceptions of water rather than two concepts. I'm not sure there is any well-recognised way of expressing my point. 'Conceptions' are usually taken to be rival accounts of the meaning of a concept, which is not what I mean to imply. In my view the two concepts or conceptions are merely different and not rivals.

${ }^{25}$ However, 'milk' is an important concept in zoology. 'Oxygen' seems like a pure scientific concept, but in ordinary usage we are usually speaking not of the element oxygen but of gaseous $\mathrm{O}_{2}$, which is important medically. The concept of food seems to have two formal elements: it is that which is nutritious (a prudential feature), and that which tastes good (an aesthetic feature). But if forced to choose between these properties, we choose the nutritious ahead of the pleasant-tasting.
} 
This discussion illustrates how scientific concepts form a distinctive family of concepts. Chemistry, like the other sciences, and like meteorology in Kovesi's tak discussion, is an explanatory enterprise. The philosophers' debate about the concept of water may arise in part from the assumption that water-as- $\mathrm{H}_{2} \mathrm{O}$ is a sheerly descriptive concept. That is, it may be being assumed that we can talk about the concept of water without situating that concept in its relevant family. But this is a mistake. Water-as- $\mathrm{H}_{2} \mathrm{O}$ is part of the science of chemistry and the point of natural science is not just to describe but also to explain the 'natural' or mind-independent world. Kovesi held as a crucial point in the philosophy of meaning that no concepts are sheerly 'descriptive'. ${ }^{26}$ No scientific concepts are mere or sheer descriptions. The explanatory point or purpose of science governs the formation of these concepts - that is, their formal elements. Explanation in science requires that we pick out those features of the world that are invariant in diverse circumstances and that possess causal powers. The science of water is an attempt to discover what is invariant and powerful in the chemical constitution of water.

Putnam's essay on meaning illustrates what happens when we lose sight of the families that concepts belong to. He generally assumes that there is only one kind of water and that it is $\mathrm{H}_{2} \mathrm{O}$. However, he does at one point consider the possibility that there might be more than one kind of water. As an analogy suggestive of this possibility, he discusses the case of jade. He observes that 'Although the Chinese do not recognize a difference, the term "jade” applies to two minerals: jadeite and nephrite. Chemically, there is a marked difference. ${ }^{27}$ However, at this point, following Kovesi, we should ask what family of concepts the concept of jade belongs to. What, to put it differently, is the formal element of the concept? Putnam does not ask this. Perhaps in past times the Chinese did not draw any sharp distinction between

\footnotetext{
26 ' In fact my view is that whenever we use a term composed of formal and material elements we describe - but never from the descriptive point of view. It does not follow from this that we can never know the facts, only that we always want to know the facts for some reason. This is what puts moral notions alongside all other notions. In all cases we group together certain facts about the world or ourselves or our activities, but in different cases we do this for different reasons and with different consequences' (MNP, p. 105).

${ }^{27}$ A useful comparison is with the concept of 'sand'. Sand is sometimes white beach sand, made largely of calcium carbonate. Sometimes it is black beach sand, made of volcanic rocks. Sometimes it is inland sand, made largely of silicon dioxide (quartz). All are kinds of sand, and there are other kinds. The diverse chemistry is irrelevant to the semantics. The chemical components are what Kovesi called the material elements of the concept (a notion discussed further below).
} 
the two kinds of jade because both forms served the purpose of jade as a precious decorative stone equally well. For them, perhaps, the concept of jade is formed from an aesthetic point of view, just as the concept of water is in part formed from a food and survival point of view. But once the chemistry of jade is found to be polymorphic, the possibility arises of distinguishing different kinds of jade, with different sorts of value. And it does seem that scientific discoveries occasioned a complete reevaluation of jade jewellery by the Chinese. ${ }^{28}$ This means that our employment of concepts in one area of discourse is not disconnected from - and perhaps often cannot be disconnected from - other areas of discourse. Jade will remain primarily an ornamental stone, but other values will enter into its conceptualisation. The comparison here between jade and water shows that what Putnam calls 'superficial' properties should not be lumped into a single basket. What counts as superficial is dependent on the point or purpose of the concept. Such supposedly superficial properties may have aesthetic or nutritional or monetary or ritual or other value, for which purposes different surface properties are picked out and categorised. ${ }^{29}$

Saying this is acknowledging Kovesi's simple but vital point that our concepts serve various purposes. These purposes play the role of determining how and why we pick out the particulars when we are using a concept. Philosophers too often try to talk about concepts without talking about their points or purposes. Most concepts in fact have only one point or purpose, but nothing prevents them from having more than one, as can happen when concepts derived from our food catalogue come to be incorporated into our scientific vocabulary. Concepts are forms of rational classification, but the rationales behind our concepts are various, since we have various needs that our concepts serve. Sometimes those different needs partially intersect, as in the case of water. But such intersection presupposes the nonintersecting cases, and so somewhat complex examples like water aren’t and can’t be the normal case.

\section{Factitious Concepts}

\footnotetext{
${ }^{28}$ See http://en.wikipedia.org/wiki/Jade. Thanks to John Williams for clarifying this section. I am grateful to him also for forcing me to find clearer ways of designating terms, concepts and substances throughout.

${ }^{29}$ Suppose you are dying of thirst in the desert. You can either drink a glass of vodka or eat a tomato. Superficially, vodka seems more like water than does the tomato, but the vodka would dehydrate you even further, whereas the tomato might save your life.
} 
Amongst philosophers, the concept of water is a key exhibit in the enterprise of developing a theory of 'natural kind concepts', which corresponds to what I am calling 'scientific concepts'. ${ }^{30}$ The enterprise is perfectly fine, but discussion of it soon turns to Putnam's twin earth thought experiments. ${ }^{31}$ These thought experiments involve discussion of what we can uncontroversially term factitious or 'made-up' concepts. In this case the factitious concept is designated by Putnam's invented term 'XYZ', which is supposedly in some sense the counterpart of 'water' in some other world, which from our viewpoint from this world we have to call 'twin water'. I think that Kovesi's account of concepts helps us to see what is happening in this peculiar experiment.

The first question to ask is whether Putnam's putative concepts of twin water and XYZ are concepts at all. Without some further explanation, 'twin water' and 'XYZ' are names, not concepts. They are the names of tokens in a philosophical problem. Until some point beyond this is specified, we can say nothing about their semantics. A further problem is that the term ' $\mathrm{XYZ}$ ' is not a term in our language (unlike 'twin water'), but merely a formula that acts as a stand-in for some future chemical concept, formulated in our existing chemical lexicon, the lexicon of the periodic table. So there are a number of difficulties in coming to grips with Putnam's puzzle.

Following the Kovesian approach, we need to know the point of the concept, and not just its point in the problem. As Kovesi observed:

[W]e do not start forming a new notion by first inventing a new word and specifying the recognitors that will enable us to answer the question 'Is this an $x$ ?' and then trying to think how we could use the word or what rules we could give for the proper use of that word. We start forming a new notion by a process which is the reverse of this. ${ }^{32}$

We must first have a reason or reasons for wanting to form a concept. These reasons will be public and will give us the rules for the proper use of the term. They will allow

\footnotetext{
${ }^{30}$ The other standard example is the concept of gold.

${ }^{31}$ See footnote 10 above.

${ }^{32}$ MNP, p. 33.
} 
us to discover whether there is more than one kind of twin water and one kind of XYZ. They will determine for us what other concepts are the same as twin water or XYZ. They will situate 'twin water' and 'XYZ' in their family or families of concepts. All this being done, we will have then have a genuine, and not a merely factitious concept, in the pejorative sense of that term. And we will also thereby know whether or in what sense 'twin water' and 'XYZ' are the same as or different from what we normally mean by 'water' and ' $\mathrm{H}_{2} \mathrm{O}$ '. If Putnam's invented concepts of twin water and XYZ are simply factitious and reason-free concepts, concepts with no formal element, nothing further could be said about how far they might fit into our conceptual scheme. And in that case, 'Whereof one cannot speak, thereof one must be silent. $^{33}$

If, however, the point or formal element of the concept of twin water is a scientific one, then it may be true that the substance XYZ is its one and only substance named by that concept. However, one would want to be given good reasons why there is only one kind of twin water, since terrestrial water has many forms, and is not just $\mathrm{H}_{2} \mathrm{O}$. Assuming XYZ is the only form of water on Twin Earth, and that 'twin water' is a scientific concept, then the concept of XYZ as used on Twin Earth resembles our scientific concept of water only in so far as, chemically speaking, it is the concept of what is similar to the oxides of hydrogen. Of course, pursuing that line of thought would require some chemical analysis, to locate the dummy term 'XYZ' in the framework of our periodic table. If we are dealing with scientific concepts, then the similar surface properties of water and twin water are simply coincidental resemblances, implying nothing about the underlying natures of the substances.

If, on the other hand, the point or formal element of the concept twin water is a food point, then it resembles our everyday notion of water in so far as it is a lifesustaining liquid, even if the forms of life on Twin Earth are not even carbon-based. In that comparison, the similar-or-different chemistry of the substances is irrelevant to whether we count twin water as water. However, as not all potable terrestrial liquids are water - consider milk, juice and beer - we would need to know whether twin

\footnotetext{
${ }^{33}$ Wittgenstein, Tractatus Logico-Philosophicus, Proposition 7. Compare Kovesi: 'our language is not about that world in which there is no value or no tables, houses, accidents or inadvertent acts. That world, the world of raw data, cannot be described for the sense of that world also lies outside it and the very description of it, likewise, lies outside it. Thereof one really cannot speak' (MNP, p. 17-18).
} 
water resembles one of these more than it resembles drinking water before we could properly classify twin water as a counterpart to what we call water.

All this being done, no further mystery will remain, at the conceptual level, about twin earth cases, though of course much would remain to be done at the chemical level. Putnam started by taking the meaning of our concept of water as straightforward, and then presented the concept of twin water as problematic. The first step was a mistake: our concept of water is not simply cashed out as $\mathrm{H}_{2} \mathrm{O}$, and is in fact an interestingly complex concept. And the concept of twin water raises no complexities greater than those raised by our concept of water. Further, the methods for dealing with our concept, derived from Kovesi's account of meaning, are the methods for dealing with the concept of twin water.

Kovesi's account of meaning is in some respects highly orthodox. It is a development of the doctrines that meaning is a matter of common public usage and that sense determines reference. Putnam's account of meaning is a challenge to the latter doctrine. Yet, curiously, his essay ends with some proposals that are close to Kovesi's account. ${ }^{34}$ He proposes (following Jerry Fodor and Jerrold Katz) that concepts are to be understood in large part by their 'semantic markers'. The semantic markers of our concept of water are, he says, 'natural kind' and 'liquid'. We have seen that matters are not so straightforward. In one sense, 'water' is a natural kind term, but not necessarily liquid; in another it is not a natural kind term, but it is a liquid. But to say this is not to question that we understand concepts in terms of their 'semantic markers', a term not dissimilar to Kovesi’s 'formal element'. But Putnam also wants to make coextensionality part of the meaning of a concept. About this Kovesi's view is very different: we can understand concepts well without knowing anything much about their extensions.

\section{Two Theories of Concepts}

The theory of natural kinds is part of a larger philosophical question, namely: how does language manage to map onto and 'represent' what philosophers like to call 'the

\footnotetext{
34 ‘The Meaning of “Meaning”’, pp. 268-271.
} 
world'? More narrowly, how does any concept map onto the piece of the world that is its designated territory? There are two basic schools of thought on this. There are those who take the view that there must be a world-to-word correlation that makes this linguistic mapping possible. In the extreme this is the theory of conceptual empiricism. Patricia Hanna and Bernard Harrison term this Referential Realism. The opposing view is that no such one-to-one correlations can do the job required to explain how linguistic representation is possible. Hanna and Harrison term this Relative Realism. They hold that 'concepts are relative to practices', and 'as no limit can be set in principle either to human purposes or to the practices that human inventiveness may devise in their service, so no limit can be set to the invention of new concepts'. ${ }^{35}$ Kovesi took their sort of view.

\footnotetext{
Whatever might be the advantages of constructing a language that would mirror the world of data, our language functions differently from such a language. In our language, to be able to understand the significance or the meaning of a term, we have to be able to follow a rule in using that term, not to be able to perceive an entity of which our term is a name. ${ }^{36}$
}

Concepts do not operate in one-to-one correspondences even with natural kinds, much less with anything else.

We saw this lack of correspondence in the case of the concept of water. The concept in both its everyday and its scientific incarnations belongs to larger families of concepts. It is this wider affiliation from which meaning is derived, not from oneto-one world-to-word relationships. Even when we narrowed the concept of water down to its scientific version, it turns out still not to map onto the natural kind designated by the formula $\mathrm{H}_{2} \mathrm{O}$. In general, I suspect that Putnam and others have assumed that water simply is $\mathrm{H}_{2} \mathrm{O}$ because they have wanted the concept of water to be the name of a natural kind, where a natural kind is a metaphysical reality and the natural kind concept is in a one-to-one or 'naming' correspondence with this supposed reality. This causes them to skate over the complex semantics of the word.

\footnotetext{
${ }^{35}$ Patricia Hanna and Bernard Harrison, Word and World: Practice and the Foundations of Language (Cambridge: Cambridge University Press, 2004), pp. 58-60. They add that they are defending a position that 'while it offers from one point of view, a version of Relativism, offers from many other points of view a defence of rather robust kinds of Realism' (p. 60). See their final chapter, pp. 347-82. ${ }^{36}$ MNP, p. 18.
} 
The mistake is to suppose that there must be a straight road leading from language to reality. In this case, and I think in others, there is no such road.

A single term that belongs to two conceptual families is somewhat unusual, but not in itself deeply puzzling. Most concepts in fact have only one point or purpose but nothing prevents them from having more than one, as is the case when concepts derived from our food catalogue come to be incorporated into our scientific vocabulary. As Kovesi said about levers, 'If one asks in a hardware shop for a lever now, the assistant cannot go out into his backyard and look for any piece of metal that would do the job. Manufacturing, buying and selling, introduced new criteria for what will or will not be accepted as levers'. ${ }^{37}$ Concepts are forms of rational classification, but the rationales behind our concepts are various, since we have various needs that concepts serve. These include our moral needs as social beings. Sometimes those different needs partially intersect, as in the case of the formation of the concept of water. But such intersection presupposes the non-intersecting cases, and so somewhat complex examples like the concept of water aren’t and can't be the normal case.

To recapitulate, Kovesi was a moral philosopher concerned to make sense of moral concepts and moral reasoning. To do this he thought he needed a general theory of concepts. This led him to think of concepts as serving purposes. But those purposes are obviously quite diverse. These diverse purposes are what he called the formal element of the concepts, and they play the role of determining how and why we pick out particulars when we are using a concept. This required a philosophy of language such that we cannot successfully talk about concepts without talking about their points or purposes. But many in the debate about natural kind terms - that is, in the philosophy of language that came to the fore in the 1960s, around the time of Moral Notions - were committed to an approach to philosophy that had no use for discussion about the point or purpose of a concept. Thus, Kovesi's contribution to moral philosophy may have seemed to be untenable because it seemed committed to an unacceptable philosophy of scientific language. I have tried to illustrate this from the

\footnotetext{
${ }^{37} M N P$, p. 14.
} 
debate about water, and to show that in fact Kovesi's moral philosophy shows how to unravel the complexities of the Putnam problem. ${ }^{38}$

I have picked out this one controversy in the philosophy of language to try to illustrate the Kovesian approach to concepts. Kovesi's position is neither conceptual holism - the doctrine that all concepts lock together into a single system or conceptual structure and face the world en bloc; nor is it conceptual atomism - the doctrine that each concept is semantically distinct from every other concept. Rather, there are various families of concepts or semantic fields or systems of classification, each distinct from the other, though some may be close (eg. law and morals) and some may be distant (eg. science and morals). ${ }^{39}$

\section{On Water, Love and Murder}

My discussion above involved two general moves, both derived from Kovesi. The first move is this: given any concept $X$ for discussion, we should always ask how many kinds of $X$ there are. So, how many kinds of water are there? The answer, even within the narrow framework of science, is, contrary to common assumptions, not just one. There may have been only one kind; there may have been any other number; in fact, if Zemach is right, there are eighteen. ${ }^{40}$ If we want to know the nature of water, we need to be able to say how it is that those eighteen are all kinds of water. Until we know that, we can't say that we know the nature of water. In fact, looking at the various kinds of water, we are led to suppose that 'water' from a scientific point of view denotes any chemical compound made exclusively of hydrogen and oxygen. And if there are any other such compounds then, scientifically speaking, there are other kinds of water.

\footnotetext{
${ }^{38}$ But other examples of the failure to think about the point of a concept come to mind. See, for example, the discussion of personhood by Ewin and Tapper, in 'Afterword', MNP, pp. 147-155. ${ }^{39}$ I can't here try to locate that approach in the spectrum of current philosophies of language. I'd be inclined to call Kovesi's view functionalist internalist semantics, but this has individualistic overtones. For a theory of linguistic representation that fits well with Kovesi's, see Hanna and Harrison, Word and World, especially the second half of the book, pp. 193-382.

${ }^{40}$ See footnote 19 above. If we had been asking about the kinds of bacteria, there would have been many thousands of kinds. We don't need to know all the kinds of bacteria in order to understand the concept of bacteria but we do need to be open to discovering new kinds of bacteria. To illustrate with a different example, we may first form the concept of a desert from experience of sandy waterless wastes. But we may later think of sand-free icy or watery wastes as deserts.
} 
A very simple but rather more Socratic-Platonic example might help to make the point here. What is love? Given this question, some of us immediately think of romantic, boy-meets-girl love, the kind of love people (young or old) supposedly fall into. But second thoughts tell us there are a number of other kinds of love. We start to enumerate them: parental love, marital love, filial love, and so on. How does this help? It helps because it tells us that we won't be able to say we understand the concept of love until we can say why the concept is appropriate for all of these very diverse kinds of phenomena.

Of course, saying this in no way implies that romantic love must be in all respects similar to, say, parental love. Obviously, romantic lovers do not and should not treat each other as children, and even more certainly parents should not behave as romantic lovers to their offspring. This illustrates why Kovesi needed his notion of material elements, as the counterpart distinction to his notion of the formal element of concepts. The material elements of any concept are those features that may differ from one kind of the concept to another. The chemical structure of the various kinds of water (in the scientific lexicon) differs from kind to kind; these differing structures are the material elements of the concept, while the formal element is that which is invariant, their being oxides of hydrogen.

I said that two Kovesian moves were being made in my discussion of water. The second was this: given any concept under discussion, we should always ask what is the family of concepts to which this concept belongs? In the case of water, reflection suggests that it belongs to two rather different families: the chemistry family and the food family. It was through making this distinction that we came to the conclusion that sometimes $\mathrm{H}_{2} \mathrm{O}$ is not water - it is ice, or snow, or vapour, none of which is food-water. This process of locating concepts in families of concepts is another way of expressing what Kovesi meant by finding the formal element of the concept. In the case of water, we find that it has two formal elements.

Individual concepts may have conflicting demands placed upon them. How do we recognise when this is the case? One of Kovesi's tests is: ask what would count as 
the same. 'The same' as water when we are thirsty might be fruit juice or milk. ${ }^{41}$ 'The same' in the laboratory might be deuterium oxide or one of the other kinds of water. We see what counts as the same by placing the concept in the family to which, in some given context, it belongs.

What is 'the same' as love? The first and best comparison is with friendship. Making this comparison we quickly see a vital difference at the formal level: similar though they are in various ways (neither can be compelled or commanded), love, unlike friendship, can be unreciprocated and need not involve people who see themselves as equals. Further comparisons might be drawn with other kinds of voluntary enduring human relationship, such as citizenship, or collegiality, or guru worship, and so on. Even so brief a discussion as this shows what more would be required to take the problem seriously. To take it seriously involves thinking about the formal element of the concept.

The main point of Moral Notions is to argue that our moral concepts are in some ways descriptions or just like other forms of description, but all descriptions must be seen as having a rational point of some sort or other. It was written at a time when moral thinking was dominated by three supposedly great problems: of the relation between 'is' and 'ought'; of the relation between description and evaluation; and the fact/value dichotomy. In Kovesi's view, the supposed dichotomy between facts and values is nothing more than the gap between material elements and formal elements, a gap which is to be encountered in all (or almost all) conceptualisation. In this way the strategy of the book is to generalise the supposed 'problem' and then to show that there is no problem, for we can readily understand the material elements/formal elements relation in non-moral contexts and so there should be no special difficulty in understanding it in moral contexts.

Kovesi takes murder to be a standard moral concept, along with kindness, lying, revenge, inadvertence, and cheating. ${ }^{42}$ What distinguishes these from other

\footnotetext{
${ }^{41}$ What about mineral water, tonic water and soda water? Like tap water, all three are drinkable lifesupporting transparent fluids. But flavour and carbonation make a difference when we are thinking aesthetically, as we may do at the dinner table or when mixing drinks.

${ }^{42}$ On his view, good, bad, right and wrong are not standard moral concepts. Rather, they play a special role in moral thinking: 'on a higher level of the hierarchy of formal and material elements, "good”,
} 
concepts is to be found in their formal elements. Thus, one task of moral philosophy is to think through the point of these concepts. This can be done at the level of the whole family of concepts, or at the level of individual concepts. ${ }^{43}$ The point of the concept of murder can be seen if we compare it with other closely-related concepts (as we did in comparing love with friendship). The wrongness of murder is uncontroversial. Murder simply is morally wrongful killing. The proposition that 'murder is morally wrongful killing' has much the same status as the proposition that 'cars are a form of transport' and 'electrons carry a negative charge'. One who did not know the truth of these propositions could not be said to know the meanings of the terms electron, car and murder. He would fail to understand the kinds of prediction the concept 'electron' permits us to make, the kinds of uses that cars standardly have, and the moral necessity to avoid committing murder.

But the formal element of murder comes more sharply into focus when we compare it with manslaughter, on the one hand, and such things as assault, theft, fraud, dishonesty, slander and cheating, on the other hand. Manslaughter is one kind of wrongful killing but it is not the same as murder. Contrary to first appearances, murder resembles theft and assault more than it resembles manslaughter, because unlike manslaughter - murder, theft and assault all involve injustice. Murders and manslaughters may often look similar, but that is merely to say that they often share many of their material elements. From the moral point of view, murder, assault and theft share crucial features that they do not share with manslaughter. What they share is injustice. Injustice, then, is the formal element of the concept of murder. ${ }^{44}$

\section{Kovesi's Theory of Concepts}

To sum up, Kovesi's theory of concepts requires us to ask three questions of any problematic concept. Firstly, what is the point or purpose of this concept? That is

\footnotetext{
"bad”, “right” and “wrong” are not superfluous, and even when they are reminders they are not only or merely reminders. Or rather, when we say "murder is wrong” it does not merely remind us that murder is murder, but of the reason why such otherwise dissimilar activities as murdering, stealing, lying get into the same class insofar as they are all wrong or vicious' (MNP, p. 26).

${ }^{43}$ See Ewin, 'Kovesi's Moral Point of View', in this volume, for a discussion of the family of moral concepts.

${ }^{44}$ See also Ewin and Tapper, 'Afterword’, MNP, p. 167-68, and R.E. Ewin, Cooperation and Human Values: A Study of Moral Reasoning (New York: St Martin’s Press, 1981), pp. 98-118.
} 
what he meant by seeking the 'formal element' of the concept. Sometimes we will find there is more than one such point or purpose. Second, what subdivisions of the concept are there? This is relevant to making progress on the first question, because we can then ask how the various kinds of the concept - with all their various differences - come together to form the broader concept. Third, what would count as the same as our problematic concept? This requires us to think laterally, but also to think vertically, since A and B will count as the same by virtue of falling under some wider or higher description, and by looking at our problematic concept from that higher or broader vantage point we will be better able to see its point or purpose - its formal element. Putnam's discussion of concepts, especially of the concept of water, seems to fail to ask these three sorts of question with any sort of rigour.

Readers of Kovesi who see him talking of 'formal' and 'material' elements may see this as an attempt to revive an Aristotelian metaphysics. But he explicitly disavowed this intention: 'By introducing these terms I am not going to introduce any metaphysical entities' ${ }^{45}$ Brian Morrison has usefully likened Kovesi’s project to John McDowell's position in Mind and World. 'Like Kovesi, McDowell is not concerned with the metaphysics of entities, with what the world contains independent of language.’ As Morrison sees it, Kovesi’s formal-material distinction helps to articulate what McDowell calls 'our conceptual second nature'. ${ }^{46}$ This gets the main point right: Kovesi is no Aristotelian. Nevertheless, as I have tried to illustrate, in a certain way Kovesi's method of argument can be applied to metaphysical and 'natural kind' questions. The Kovesian approach to the debate about water suggests that we cannot go straight to metaphysical matters. We must first make sure that we have got our terminology clear. Semantics precedes metaphysics. And getting the language clear is a matter of following the method of formal and material questioning.

There is no algorithm or purely logical procedure for doing this sort of semantics. It can't be done by solely by the standard philosopher's method of seeking the necessary and sufficient conditions of the concept in question. In general, the

\footnotetext{
${ }^{45}$ MNP, p. 7.

${ }^{46}$ Brian Morrison, 'Mind, World and Language: McDowell and Kovesi', Ratio, 15, 2002, pp. 293-308, discussing John McDowell, Mind and World (Cambridge, Mass: Harvard University Press, 1994, expanded 1996); in this volume, pp. ***.
} 
Kovesian method cannot be formalised. ${ }^{47}$ Only in very specialised formal contexts, such as (though debatably) geometry, will there be successful definitions constructed out of sets of conditions that are severally necessary and jointly sufficient. Such cases are rare because normally there is no final and complete set of the ways of being or doing X. New ways of being or doing X may be yet to be discovered or invented; new technologies and new leaps of imagination will come into play here.

In the strategy of Moral Notions the theory of concepts is doing the philosophical work, but it is negative work, a refutation of a dichotomy that has dominated the moral field, as manifested in a variety of forms: prescriptivism, emotivism, existentialism, and perhaps postmodernism. The strategy is of course successful only to the extent that the theory of concepts is successful. On this theory, concepts are rational - and not just rule-governed - creations. They are descriptive, but not merely descriptive. They are ways of classifying the world, including the human social world and human actions, guided by our various shared human needs and interests. Those needs include our moral needs as social beings and our needs as curious inquirers into the natural world.

In this discussion I have tried to show that the strategy of Moral Notions is successful even in a debate a long way from the territory of moral philosophy. Contemporary analytical philosophers have written a great deal about water. Almost all seem to all agree that water is $\mathrm{H}_{2} \mathrm{O}$. The problem, as they see it, is to explain the relation between the two concepts. I have argued, following a Kovesian line of argument, that in this they are doubly mistaken. The doctrine that water is $\mathrm{H}_{2} \mathrm{O}$ misconstrues both the everyday concept of water and the scientific concept of water. These two very different misconstructions seem to be motivated by a more general idea, that it is possible to take a short route from semantics to metaphysics. There are no such short cuts and in this matter the longest way round is the shortest way home.

Kovesi also argued, perhaps paradoxically, that moral concepts are more objective and rational than scientific and other kinds of concepts, since in their

\footnotetext{
${ }^{47}$ 'I do not want to say that, in contrast to the unspecified material element, the formal element is always something final and definable. It is difficult to give precisely once and for all the formal element not only in the case of notions like murder but also in cases like the table' (MNP, p. 7).
} 
formation they are able to be contested, and thus rationally strengthened, by their subject matter, human beings, whereas in the other cases the subject matter, the natural world, is mute. ${ }^{48}$ But that interesting contention is not part of my current argument; it is a topic that needs a separate discussion.

48 'After all, inanimate objects cannot put up any resistance if as a result of our changed interest or changed conceptual framework we select different features of the world for special attention. We on the other hand, as users of our terms, would resist such a change when the terms are about ourselves' (MNP, p.42). 